\title{
CHARACTERIZATION OF GLYCOLIPIDS SYNTHESIZED IN AN IDENTIFIED NEURON OF APLYSIA CALIFORNICA ${ }^{1}$
}

\author{
ARIEL A. SHERBANY, RICHARD T. AMBRON, AND JAMES H. SCHWARTZ ${ }^{2}$ \\ Howard Hughes Medical Institute, Center for Neurobiology and Behavior, Departments of Anatomy and Cell Biology, Neurology, \\ and Physivlogy, College of Physicians and Surgeons, Columbia University and The New York State Psychiatric Institute,
} New York, New York 10032

Received December 27, 1983; Accepted February 7, 1984

\begin{abstract}
Because radioactive precursors can be injected directly into the cell body or axon of $\mathrm{R} 2$, a giant, identified neuron of the Aplysia abdominal ganglion, it was possible to show that glycolipid is synthesized in the cell body, inserted into membranes along with glycoprotein, and then exported into the axon within organelles that are moved by fast axonal transport. After intrasomatic injection of $N-\left[{ }^{3} \mathrm{H}\right]$-acetyl-D-galactosamine, five major ${ }^{3} \mathrm{H}$-glycolipids were identified using thin layer polysilicic acid glass fiber chromatography. At least two of the lipids are negatively charged. Analysis of ${ }^{32} \mathrm{P}$-labeled lipid from the abdominal ganglion revealed the presence of 2 -aminoethylphosphonate, indicating that these polar substances are sphingophosphonoglycolipids. The major ${ }^{3} \mathrm{H}$-glycolipids synthesized in R2 are similar to a family of phosphonolipids isolated from the skin of $A$. kurodai, previously characterized by Araki et al. (Araki, S., Y. Komai, and M. Satake (1980) Biochem J. 87: 503-510). Since sialic acid is absent in Aplysia as in other invertebrates, these polar glycolipids may function like gangliosides in vertebrates. The polar ${ }^{3} \mathrm{H}$-glycolipids are synthesized and incorporated into intracytoplasmic membranes solely in the cell body. Direct injection of the labeled sugar into the axon revealed no local synthesis or exchange of glycolipid. Moreover, there was no indication for transfer from glial cells into axoplasm. Although the incorporation of $N$ - $\left[{ }^{3} \mathrm{H}\right]$-acetyl-D-galactosamine into glycolipid is not affected by anisomycin, an effective inhibitor of protein synthesis, the export into the axon of membranes containing the newly synthesized lipid is completely blocked by the drug. This can be explained if a cellular mechanism operates that permits the export only of organelles with a normal complement of lipid and protein. When exported into the axon, the ${ }^{3} \mathrm{H}-$ glycolipids are transported at a rate of at least 40 to $70 \mathrm{~mm} /$ day at $15^{\circ} \mathrm{C}$.
\end{abstract}

Proteins are synthesized in the neuronal soma. Those destined for the axon or synaptic terminals are packaged into organelles to be rapidly transported from the cell body (see Grafstein and Forman, 1980). Lipids also are important components of synaptic membranes, but it remains to be determined whether they all originate in the cell body or whether some can be synthesized locally in the axon or contributed by glial cells (Forman and Ledeen, 1972; Holm, 1972; Grafstein and Forman, 1980). Experiments to answer this question are difficult to perform in heterogeneous and complex nervous tissue. We have previously examined the origin of vesicle glycoproteins using R2, an identified giant neuron of Aplysia

\footnotetext{
${ }^{1}$ Supported by National Institutes of Health Research Grants NS14555 and NS 19332. R. T. A. was supported by a United States Public Health Service Career Development Award, and A. A. S. was a trainee of the Public Health Service Medical Scientist Training Program supported by Grants GMO-1668 and GMO-7308.

${ }^{2}$ To whom correspondence should be addressed.
}

californica (Ambron et al., 1981a). R2's cell body is the largest in the abdominal ganglion $(0.8 \mathrm{~mm}$ in diameter), and its axon runs unbranched in the right pleuroabdominal connective, ultimately to synapse on glands in the animal's skin (Rayport et al., 1983).

In this report, we extend our earlier work (Sherbany et al., 1979) on the source of R2's membrane glycolipids. ${ }^{3} \mathrm{H}$-labeled sugars which serve as glycolipid precursors can be injected directly into R2's cell body or axon. Since incorporated radioactivity is restricted to the injected neuron, regional synthetic capabilities can be determined unambiguously (Ambron et al., 1974a; Thompson et al., 1976; Sherbany et al., 1979). The glycoproteins and glycolipids of the glial cells and connective tissue that surround axons can also be labeled preferentially by incubating connectives in the presence of radioactive precursors (Ambron and Treistman, 1977). Consequently, it is possible to examine unequivocally the origin of the glycolipids that are rapidly transported in membranous organelles along R2's axon. In addition, they 
can be characterized chemically. Gangliosides, which are important in the vertebrate nervous system (Fishman and Brady, 1976; Ledeen et al., 1976; Yamakawa and Nagai, 1978), appear to be absent from Aplysia (Komai et al., 1973). Instead, we have found a class of phosphonoglycolipids that may serve the same functions as do gangliosides in vertebrates.

\section{Materials and Methods}

A. californica weighing 70 to $200 \mathrm{gm}$ (supplied by Pacific Biomarine Supply Corp., Venice, CA) were maintained at $15^{\circ} \mathrm{C}$ in aerated, filtered Instant Ocean (Aquarium Systems, Eastlake, $\mathrm{OH}$ ).

Incubation of nervous system in labeled sugar. Isolated abdominal ganglia with nerves and connectives attached were incubated at $15^{\circ} \mathrm{C}$ in $0.5 \mathrm{ml}$ of sterile-filtered artificial sea water supplemented with amino acids (Eisenstadt et al., 1973). $N-\left[\mathrm{G}-{ }^{3} \mathrm{H}\right]$-Acetyl-D-galactosamine $\left(\left[{ }^{3} \mathrm{H}\right] \mathrm{GalNAc}, 25 \mathrm{Ci} / \mathrm{mmol}\right)$ and $\mathrm{L}-\left[1{ }^{11} \mathrm{C}\right]$ fucose $(50 \mathrm{mCi} /$ mmol), purchased from New England Nuclear (Boston, MA), were added at a concentration of $4 \mu \mathrm{M} ; 1 \mathrm{pmol}$ of $N-\left[{ }^{3} \mathrm{H}\right]$ acetylgalactosamine was equivalent to 10,500 cpm. Carrier-free ${ }^{32} \mathrm{P}_{\mathrm{i}}$ (Amersham, Arlington Heights, IL) was used in supplemented sea water with $\mathrm{Ca}^{++}$omitted.

Intrasomatic and intra-axonal injection. Double-barreled electrodes for injecting $\left[{ }^{3} \mathrm{H}\right]$-GalNAc into R2's cell body (Eisenstadt et al., 1973) and axon (Treistman and Schwartz, 1977) were prepared as previously described. After injection, the nervous system was maintained at $15^{\circ} \mathrm{C}$ in supplemented sea water. In some experiments, 4 to $5 \mathrm{hr}$ before the intrasomatic injection, the isolated nervous system was exposed to $18 \mu \mathrm{M}$ anisomycin (Ambron et al., 1975). R2 was also injected in intact animals anesthetized with isotonic $\mathrm{MgCl}_{2}$. An incision was made just beneath the right parapodium, and the abdominal ganglion was pinned to a stage at the end of a Lucite rod illuminated by fiber optics. After injection, the incision was sutured, and the animal was placed in a small aquarium (Sherbany, 1981). Recovery was ascertained by active movement and feeding.

Dissection of R2's cell body and extrusion of axoplasm. The cell body was dissected from the ganglion and separated from surrounding neurons and neuropil. 'The intact nucleus, cytoplasm, and external envelope, consisting of R2's plasma membrane and associated glial cells, were isolated separately for fractionation (Ambron, 1982). The right connective, severed from the abdominal ganglion, was placed in $0.1 \mathrm{ml}$ of $\mathrm{Ca}^{++}$-free, supplemented artificial sea water containing $50 \mathrm{~mm}$ EGTA at $4^{\circ} \mathrm{C}$. Axoplasm was extruded by drawing the connective gently through the tines of a forceps. Axoplasm and the remaining tissue in the connective were then fractionated separately.

Morphological techniques. Tissue was fixed in $6 \%$ glutaraldehyde- $0.2 \mathrm{M}$ collidine, postfixed in $1 \%(\mathrm{w} / \mathrm{v}) \mathrm{OsO}_{4}$, dehydrated, and embedded in Epoxy resin. Sections were stained with lead citrate and aqueous uranyl acetate and were examined on a Phillips EM 301 electron microscope (Thompson et al., 1976).

\section{Biochemical procedures}

Fractionation. Details of the fractionation procedure have been described (Ambron et al., 1981a; Sherbany, 1981). Because injected radioactive sugar precursors are incorporated only within the injected cell, and because labeled macromolecules remain localized to the cell and its axons (Ambron et al., 1974a; Thompson et al., 1976; Ambron and Treistman, 1977; Sherbany et al., 1979), it was not necessary to separate the cell body or axon from the tissue for radiochemical analysis. Ganglia or connectives were homogenized and centrifuged at 105,000 $\times g$. The supernate was treated with $5 \%$ trichloroacetic acid (TCA)-0.5\% phosphotungstic acid, and the precipitate containing soluble glycoprotein was collected and counted.

The tissue pellet was sequentially treated at $4^{\circ} \mathrm{C}$ with $30 \mathrm{vol}$ of chloroform:methanol (C:M) 2:1, followed by 1:2 (v/v) to extract ${ }^{3} \mathrm{H}$-glycolipids quantitatively. After lipids were removed, ${ }^{3} \mathrm{H}$-glycoproteins were extracted from the pellet with $3 \%$ sodium dodecyl sulfate (SDS), $5 \% 2$ mercaptoethanol at $70^{\circ} \mathrm{C}$. The small amount of residual glycoprotein was solubilized with $90 \%$ aqueous formic acid. The sum of the radioactivity in these extracts was taken as the particulate glycoprotein content of the neuron. All of the radioactivity in $\mathrm{R} 2$ is recovered by these procedures.

Isolation of glycolipid. ${ }^{3} \mathrm{H}$-Lipids were fractionated on a silicic acid column $(1.5 \times 40 \mathrm{~cm})$ (Rouser et al., 1967) by sequential elution with chloroform; chloroform: methanol, 2:1 and 1:2; and chloroform:methanol: water (C:M:W) 10:10:3. ${ }^{3} \mathrm{H}$-Glycolipids A and B were eluted together from the silicic acid column with $\mathrm{C}: \mathrm{M}: \mathrm{W}$, 10:10:3. They were concentrated under $\mathrm{N}_{2}$ and then chromatographed on a column of DEAE-cellulose (DE 52 , Whatman). Both ${ }^{3} \mathrm{H}$-glycolipids were eluted from this column with C:M:ammonium carbonate (10:10:3).

Thin layer chromatography. Best resolution of the ${ }^{3} \mathrm{H}$ glycolipids was obtained with polysilicic acid glass fiber sheets (ITLC-Type 5A, Gelman, Ann Arbor, MI) developed with 1-propanol:water (P:W 80:20). After the chromatogram was dry, it was developed again with $1 \%$ aqueous sodium tetraborate (modified from Chien et al., 1973). Under these conditions, the lipids did not migrate, but nucleotide sugars, oligosaccharides, and glycopeptides produced by pronase digestion of Aplysia glycoproteins all moved with the solvent front (Sherbany, 1981).

Ion exchange paper chromatography. ${ }^{3} \mathrm{H}$-Glycolipids were analyzed by ascending paper chromatography on ion exchange papers (Whatman CM82, DE81, and ET81) in $\mathrm{C}: \mathrm{M}: \mathrm{W}$ 10:10:3.

Acid hydrolysis. ${ }^{3} \mathrm{H}$-Glycolipids extracted from the $105,000 \times g$ membrane pellet were hydrolyzed in $4 \mathrm{~N} \mathrm{HCl}$ at $105^{\circ} \mathrm{C}$ for $8 \mathrm{hr}$. Under these conditions, $\left[{ }^{3} \mathrm{H}\right]$ GalNAc is completely deacylated to $\left[{ }^{3} \mathrm{H}\right]$ galactosamine. The hydrolysate was chromatographed in the descending direction using ethyl acetate:pyridine:acetic acid:water (5:5:1:3), a system that separates glucosamine from galactosamine (Ambron et al., 1981b).

Methanolysis. Saponification of ${ }^{3} \mathrm{H}$-glycolipids was carried out in $0.1 \mathrm{M}$ methanolic $\mathrm{KOH}$ for $15 \mathrm{~min}$ at $37^{\circ} \mathrm{C}$ 
(Ambron and Pieringer, 1971). After adding water, the organic and aqueous phases were chromatographed on ITLC.

Enzymatic digestions. Digestion was carried out directly on ITLC sheets (modified after Naughton and Hagopian, 1962). Material to be digested was applied together with $5 \mathrm{mg}$ of pronase (beta grade, Cal Biochem, San Diego, CA) and $5 \mu \mathrm{g}$ of bovine serum albumin labeled with Fluram (Roche Laboratories, Nutley, NJ) added to serve as a monitor for digestion. The plate was then sprayed with ammonium carbonate buffer until damp and suspended horizontally at $37^{\circ} \mathrm{C}$ in a sealed chamber. After $24 \mathrm{hr}$, the plate was dried and developed with P:W $80: 20$, followed by $1 \%$ aqueous sodium tetraborate. Similar experiments were carried out at $25^{\circ} \mathrm{C}$ with Escherichia coli alkaline phosphatase and phosphodiesterase I (type IV, Crotalus venom) both from Sigma Chemical Co. (St. Louis, MO).

\section{Results}

Appearance of ${ }^{3} \mathrm{H}$-glycolipid in R2's axon. Following a short lag after injection of $\left[{ }^{3} \mathrm{H}\right]$ GalNAc into R2's cell body, increasing amounts of labeled glycolipid were found in the axon; in contrast, soluble radioactivity appeared in the axon almost immediately (Fig. 1). At each time period examined, all of the ${ }^{3} \mathrm{H}$-glycolipid in both cell body and axon was particulate (Table I), implying that the glycolipid is associated with membranes. ${ }^{3} \mathrm{H}-\mathrm{Mem}$ brane glycoprotein was also synthesized in R2 after injection of $\left[{ }^{3} \mathrm{H}\right]$ GalNAc. When the export of newly made glycoprotein and glycolipid was examined in the same cell, both classes of glycoconjugate appeared in the axon with similar kinetics (Fig. 2). Coordinated movement would be expected if the glycoprotein and glycolipid are components of the same transported organelles (see be-
TABLE I

Distribution of particulate radioactivity in the cell body and axon of $R 2$ after intrasomatic injection of $\left[{ }^{3} \mathrm{H}\right] \mathrm{GalNAc}$

At the times indicated after injection, the nervous system was frozen, the injected cell body was marked, and the right connective containing R2's axon (with the proximal region of axon within the abdominal ganglion adjacent to the cell body) was separated from the rest of the ganglion which contained the cell body. The tissues containing the cell body and axon were homogenized and fractionated separately (see "Materials and Methods"). No significant chloroform:methanol-extractable radioactivity was found in the supernatant. Radioactivity in both the cell body and the axon is expressed as a percentage of the total radioactivity in the neuron. The average amount of radioactivity in the neuron was $19.4 \mathrm{pmol}$.

\begin{tabular}{|c|c|c|c|c|}
\hline Time & $\begin{array}{c}\text { No. of } \\
\text { Experiments }\end{array}$ & & Glycolipid & Glycoprotein \\
\hline$h r$ & & & \multicolumn{2}{|c|}{$\begin{array}{l}\text { Percentage of total radioactivity } \\
\text { in the neuron }\end{array}$} \\
\hline \multirow[t]{2}{*}{1} & 3 & Cell body & $0.56 \pm 0.07$ & $1.05 \pm 0.19$ \\
\hline & & Axon & $0.04 \pm 0.02$ & $0.07 \pm 0.02$ \\
\hline \multirow[t]{2}{*}{5} & 8 & Cell body & $6.80 \pm 0.81$ & $18.03 \pm 2.48$ \\
\hline & & Axon & $0.48 \pm 0.12$ & $1.00 \pm 0.28$ \\
\hline \multirow[t]{2}{*}{10} & 5 & Cell body & $6.42 \pm 0.78$ & $20.57 \pm 2.06$ \\
\hline & & Axon & $0.99 \pm 0.05$ & $5.53 \pm 0.52$ \\
\hline \multirow[t]{2}{*}{15} & 5 & Cell body & $7.38 \pm 2.06$ & $19.15 \pm 2.21$ \\
\hline & & Axon & $3.46 \pm 1.07$ & $15.04 \pm 3.95$ \\
\hline \multirow[t]{2}{*}{22} & 5 & Cell body & $7.02 \pm 0.95$ & $24.17 \pm 2.30$ \\
\hline & & Axon & $4.54 \pm 0.84$ & $16.35 \pm 2.25$ \\
\hline \multirow[t]{2}{*}{46} & 3 & Cell body & $6.41 \pm 1.23$ & $13.80 \pm 2.92$ \\
\hline & & Axon & $12.9 \pm 1.16$ & $22.31 \pm 2.97$ \\
\hline
\end{tabular}

${ }^{a}$ Values are mean \pm SEM.

low) and presuming that glycolipid, like glycoprotein, is synthesized only in the cell body.

The labeled glycolipids from R2's cell body were similar to those that later appeared in the axon (Fig. 3). Five glycolipids were resolved by polysilicic acid glass fiber chromatography (ITLC), three of which are highly polar.

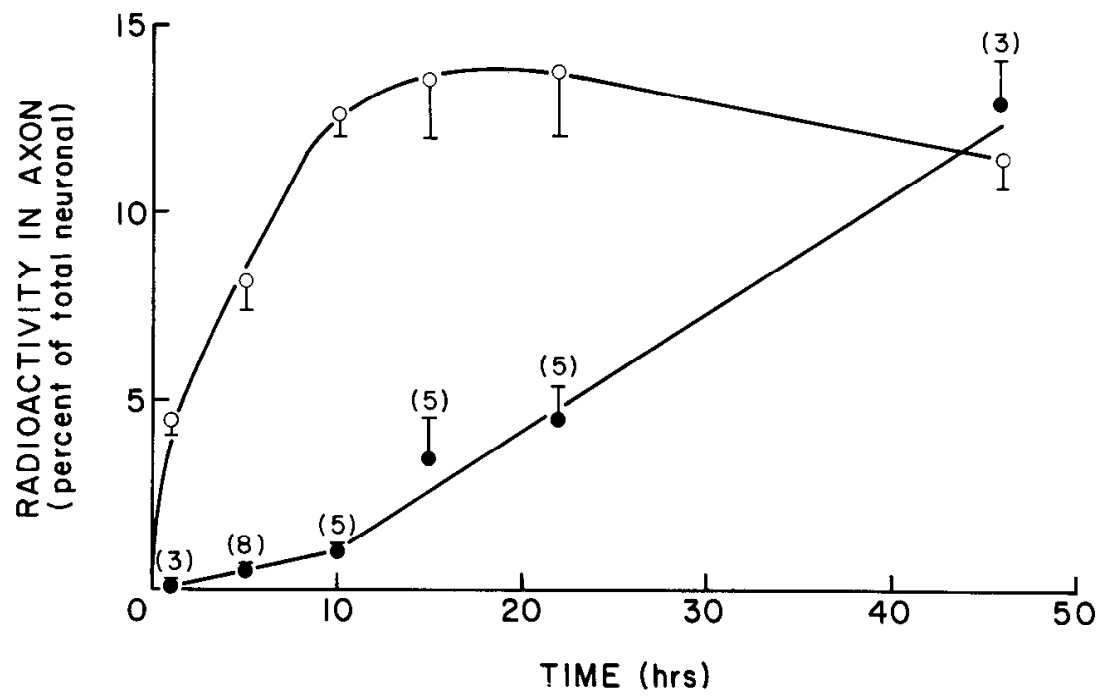

Figure 1. Appearance of 'H-glycolipid in R2's axon. At the times indicated after intrasomatic injection of $\left[{ }^{3} \mathrm{H}\right] \mathrm{GalNAc}$, the cell body and axon were separated and fractionated (see "Materials and Methods"). Radioactivity appearing in glycolipid (O) and the acid-soluble fraction $(O)$ in the axon is expressed as a percentage of the total radioactivity in the neuron (cell body and axon combined). Error bars denote standard error of the mean (SEM). 


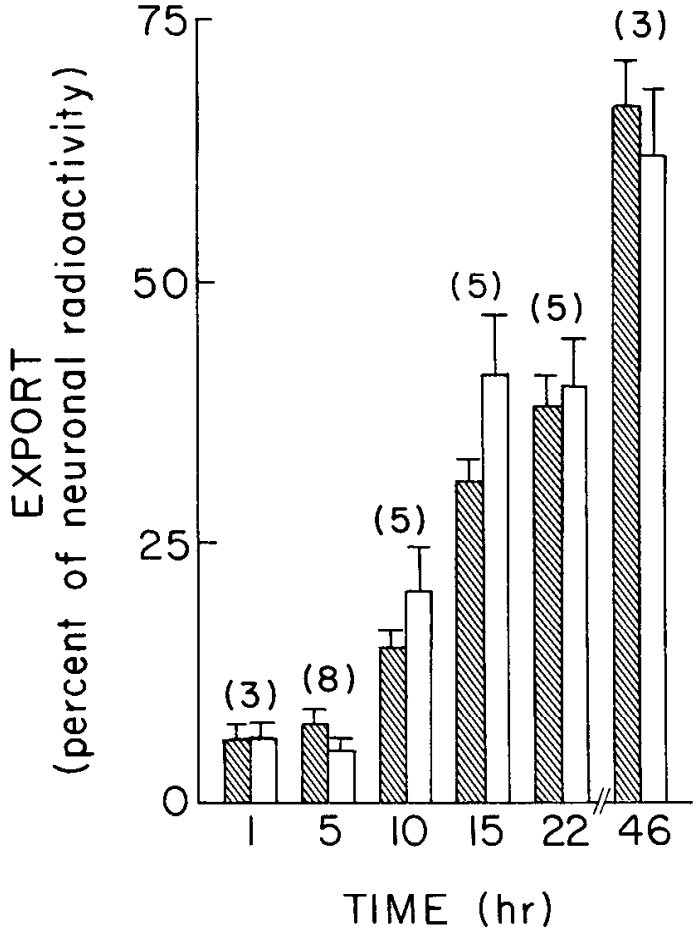

Figure 2. Comparison of the export of ${ }^{3} \mathrm{H}$-glycolipid with that of ${ }^{3} \mathrm{H}$-glycoprotein into $\mathrm{R} 2$ 's axon. At various times after intrasomatic injection of $\left[{ }^{3} \mathrm{H}\right] \mathrm{GalNAC}$, the cell body and axon were fractionated separately and glycoconjugates were extracted. Export is calculated as the percentage in the axon of the total radioactivity of glycoconjugate in the neuron. Hatched bars denote glycolipid; open bars denote glycoprotein. Error bars denote SEM. The values in parentheses indicate the number of experiments.

The same glycolipid classes were synthesized when R2 was injected with $\left[{ }^{3} \mathrm{H}\right] \mathrm{GalNAc}$ in intact animals (see "Materials and Methods") and, therefore, are normal constituents of that neuron.

Characterization of ${ }^{3} \mathrm{H}$-glycolipids. The lipid nature of the labeled species is indicated by their solubility in organic solvents and their failure to migrate on thin layer chromatography with aqueous sodium tetraborate which causes water-soluble compounds to move to the solvent front. Upon methanolysis, which removes fatty acyl esters from glycerolipids, less than $5 \%$ of the radioactivity in the ${ }^{3} \mathrm{H}$-glycolipid fraction was released, and the chromatographic mobility of the five glycolipids was unchanged. Resistance to saponification is an indication that the compounds are sphingolipids.

Glycolipids A and B were isolated by column chromatography using silicic acid and DEAE-cellulose. Both components required high salt to be eluted from the ion exchange column. In addition, both remained at the origin of a cation exchange paper but migrated on anion exchange paper, indicating that they are negatively charged. To show that the anionic moiety is phosphate, Aplysia ganglia were exposed to ${ }^{32} \mathrm{P}_{\mathrm{i}}$ and the lipid fraction was separated by ITLC. Most of the radioactivity migrated near the front as expected of glycerol phospholipids, but two components had the same mobility as ${ }^{3} \mathrm{H}$ glycolipids A and B (Fig. 4). Radioactivity migrating with ${ }^{3} \mathrm{H}$-glycolipid A was eluted from the chromatogram and hydrolyzed in acid. Several labeled compounds remained after hydrolysis, but most of the radioactivity migrated with 2-aminoethylphosphonate (Fig. 5); a similar result was obtained with glycolipid B (not shown). The identity of the other ${ }^{32} \mathrm{P}$-labeled compounds on the chromatogram has not been determined, but it is not $P_{i}$. Araki et al.

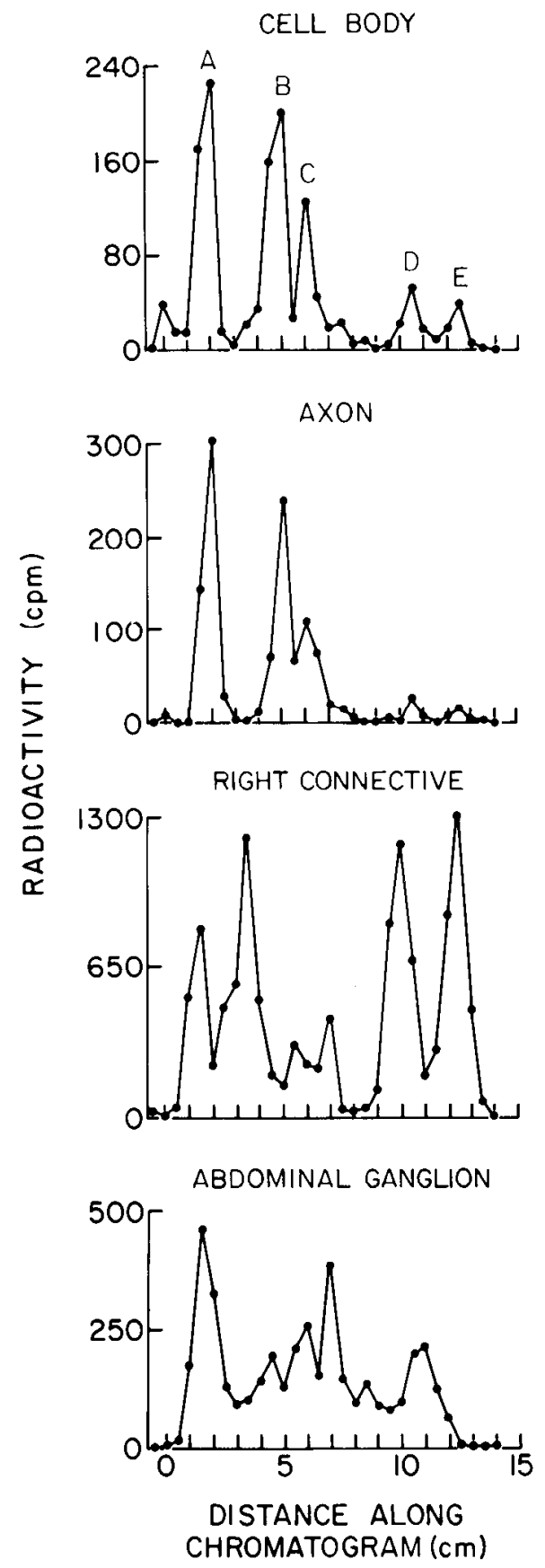

Figure 3. Chromatography of ${ }^{3} \mathrm{H}$-glycolipids on polysilicic acid glass fiber plates (ITLC) developed with 1-propanol:water. Cell body, ${ }^{3} \mathrm{H}$-glycolipid extracted from R2's cell body membranes $22 \mathrm{hr}$ after intrasomatic injection of $\left[{ }^{3} \mathrm{H}\right]$ GalNAc. Axon, ${ }^{3} \mathrm{H}$-glycolipids extracted from axonal membranes of the same neuron whose somatic lipids are shown above. Right connective, ${ }^{3} \mathrm{H}$-glycolipid extracted from membranes of the right connective after incubation in $\left[{ }^{3} \mathrm{H}\right]$ GalNAc. Abdominal ganglion, ${ }^{3} \mathrm{H}$-glycolipid extracted from the membranes of the ganglion after incubation in $\left[{ }^{3} \mathrm{H}\right]$ GalNAc. 


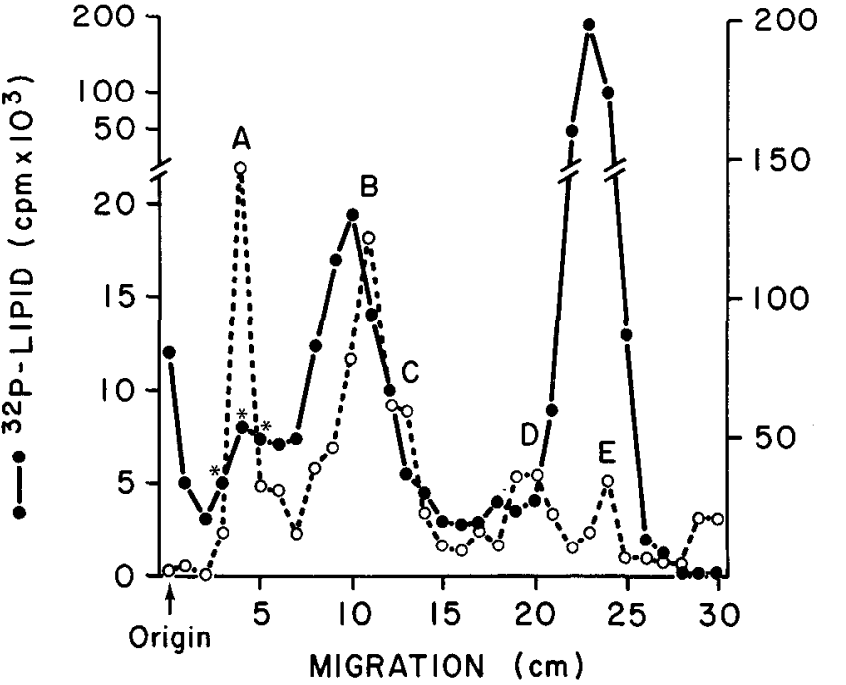

Figure 4. Chromatography of ${ }^{32} \mathrm{P}$-labeled lipid on ITLC. An abdominal ganglion was incubated with $0.5 \mathrm{mCi}$ of ${ }^{32} \mathrm{P}_{\mathrm{i}}$ for 24 $\mathrm{hr}$ at $15^{\circ} \mathrm{C}$. After fractionation, the ${ }^{32} \mathrm{P}$-labeled lipids were chromatographed. For comparison, ${ }^{3} \mathrm{H}$-glycolipids formed after intrasomatic injection of $\left[{ }^{3} \mathrm{H}\right] \mathrm{GalNAc}$ were chromatographed in an adjacent lane. The chromatogram was dried, and each lane was cut into $0.5-\mathrm{cm}$ segments for counting. The asterisks denote samples of ${ }^{32} \mathrm{P}$-lipid eluted from the chromatogram for acid hydrolysis (see Fig. 5 below).

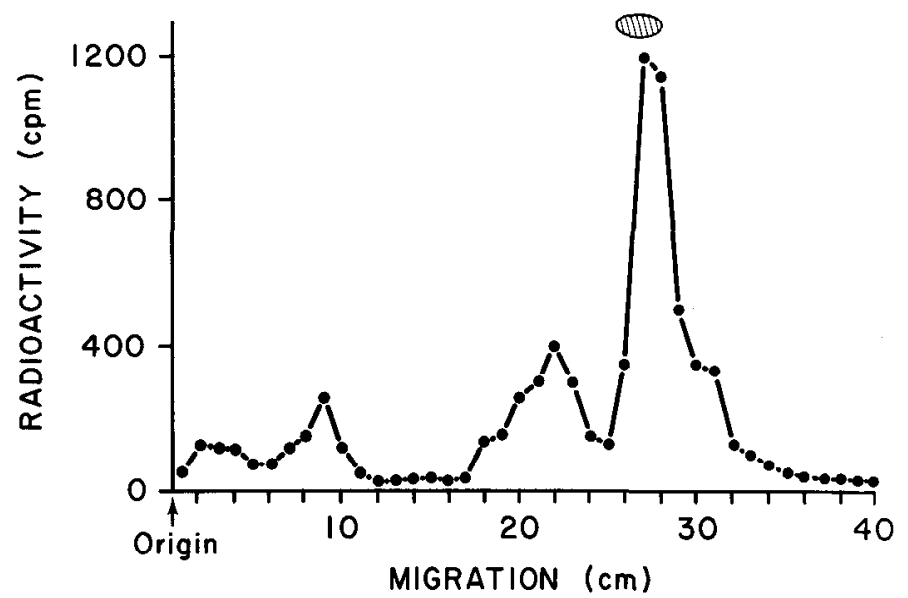

Figure 5. Chromatography of products of acid hydrolysis of ${ }^{32} \mathrm{P}$-labeled lipid. The ${ }^{32} \mathrm{P}$-lipid eluted from the chromatogram shown in Figure 4 was hydrolyzed in $6 \mathrm{~N} \mathrm{HCl}$ at $100^{\circ} \mathrm{C}$ for 9 hr. The hydrolyzate was lyophilized, reconstituted in water, and chromatographed in the descending direction on Whatman $3 \mathrm{MM}$ paper with 1-propanol:TCA: $\mathrm{NH}_{4} \mathrm{OH}$ :water $(75: 5: 0.3: 25$, $\mathrm{v} / \mathrm{w} / \mathrm{v} / \mathrm{v})$. The lane containing hydrolyzed lipid was cut into segments for counting and the 2-aminoethylphosphonate standard, which migrated $27 \mathrm{~cm}$, was visualized with ninhydrin.

(1980) have isolated a sphingophosphonoglycolipid from the skin of Aplysia kurodai. A sample of this lipid, designated SGL-II (generously provided by Professor M. Satake, Niigata University), migrated with ${ }^{3} \mathrm{H}$-glycolipid A in our ITLC system with P:W 80:20 and also on ITLC developed with 1-propanol:ammonium hydroxide:water (6:2:1) (not shown). According to Araki et al. (1980) and Araki and Satake (1981), SGL-II contains galactosamine, glucose, and 3-methylgalactose. Because acid hydrolysis of ${ }^{3} \mathrm{H}$-glycolipid A yielded on chromatography both la- beled galactosamine and glucosamine, we conclude that glycolipid A is a sphingophosphonoglycolipid which is similar to glycolipid SGL-II of $A$. kurodai, but that the two glycolipids probably are not identical.

Axons lack the capacity to synthesize glycolipid. To provide evidence that the ${ }^{3} \mathrm{H}$-glycolipid which appears in R2's axon originates in the cell body, $\left[{ }^{3} \mathrm{H}\right] \mathrm{GalNAc}$ was injected directly into the axon of $\mathrm{R} 2$. No ${ }^{3} \mathrm{H}$-glycolipid was formed. We found that $0.5 \%$ to $2.7 \%$ of the total radioactivity was incorporated into chloroform:methanol-extractable material. When chromatographed, a prominent component was seen which migrated $8 \mathrm{~cm}$ from the origin (Fig. 6A). This component is not a glycolipid by our criteria, however, because it moved to the front when the chromatogram was redeveloped with aqueous sodium tetraborate (Fig. $6 B$ ). The identity of this axonal component has not yet been determined, but it is not GalNAc, galactosamine, uridine diphosphate (UDP)-GalNAc, or UDP-glucosamine.

Localization of ${ }^{3} \mathrm{H}$-glycolipid to the cell body and axon of $R 2$. It was assumed in the above experiments that the ${ }^{3} \mathrm{H}$-glycolipids are localized to the injected neuron. Because of R2's large size, we were able to demonstrate this directly by dissecting R2's isolated cell body and extruding axoplasm from the right connective. In these experiments, ${ }^{3} \mathrm{H}$-glycoproteins were used as intracellular markers for the neuronal (somatic or axonal) compart-

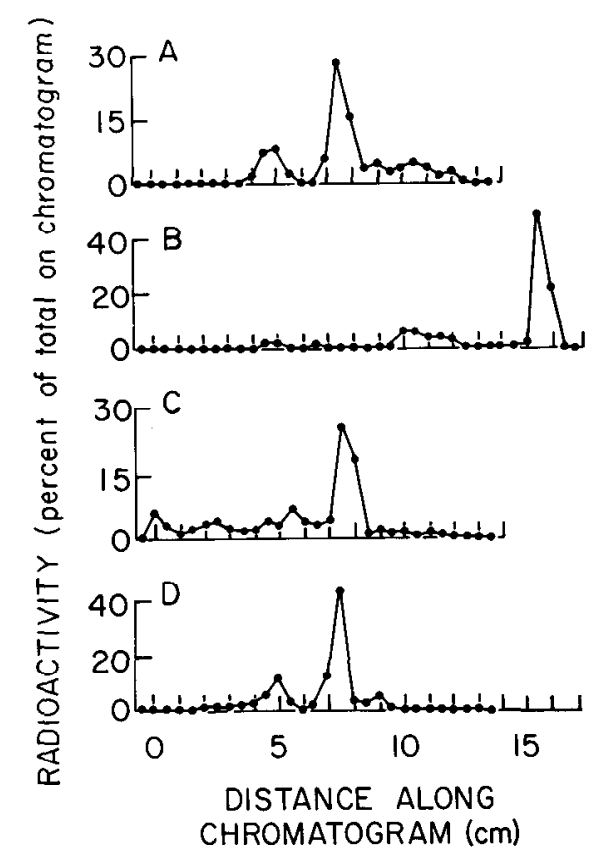

Figure 6. Chromatography of chloroform:methanol extracts of R2's axon after intrasomatic or intra-axonal injection of $\left[{ }^{3} \mathrm{H}\right]$ GalNAc. $A$, After axon injection of $\left[{ }^{3} \mathrm{H}\right]$ GalNAc and developed with propanol:water; the total radioactivity on the chromatogram was $172 \mathrm{cpm}$. $B$, A sample of the same material chromatographed in $A$ developed with propanol:water (front at $14 \mathrm{~cm}$ ) followed by development with $1 \%$ borate (front at $17 \mathrm{~cm}$ ); total radioactivity was $553 \mathrm{cpm}$. $C$, Radioactivity extracted from the segment of the axon distal to a colchicine cuff; total radioactivity was $700 \mathrm{cpm}$. $D$, Radioactivity from R2's axon after injection of $\left[{ }^{3} \mathrm{H}\right]$ GalNAc into R2's cell body in the presence of anisomycin; total radioactivity was $1089 \mathrm{cpm}$. 
ment. Autoradiography of several identified Aplysia neurons, including $\mathrm{R} 2$, has revealed that labeled glycoproteins formed after injection of ${ }^{3} \mathrm{H}$-sugars are restricted to the cell body and its processes (Thompson et al., 1976; Ambron and Treistman, 1977; Ambron et al., 1980, 1981a).

When R2's cell body was dissected, essentially all of the ${ }^{3} \mathrm{H}$-glycolipid and ${ }^{3} \mathrm{H}$-glycoprotein was contained in the isolated cytoplasm (Fig. 7A). Differential centrifugation revealed that the labeled glycoconjugates are particulate, consistent with their being associated with internal membrane systems of the cell body. When the ${ }^{3} \mathrm{H}$ glycolipids were chromatographed, the pattern obtained was identical to those shown in Figure 3 for the undissected cell body.

We next drew the right connective containing R2's main axon gently through the tines of forceps $15 \mathrm{hr}$ after intrasomatic injection of $\left[{ }^{3} \mathrm{H}\right]$ GalNAc. Electron microscopy of the connective after extrusion showed that most of the axolemma and supporting glial cells remained intact. Both ${ }^{3} \mathrm{H}$-glycolipid and ${ }^{3} \mathrm{H}$-glycoprotein were extruded to a similar extent (Fig. $7 B$ ), and the extruded ${ }^{3} \mathrm{H}$-glycolipid had the same chromatographic pattern as did the lipid left behind in the connective. This result would be expected if all of the ${ }^{3} \mathrm{H}$-glycolipid in the connective was originally present in R2's axoplasm.

Extrusion experiments also provided evidence that glycolipids synthesized in glial cells and connective tissue that surround the axon are different from those produced by $\mathrm{R} 2$. This was determined by extruding axoplasm from connectives that had been incubated in the presence of $\left[{ }^{3} \mathrm{H}\right]$ GalNAc. In contrast to injection, this mode of ad-
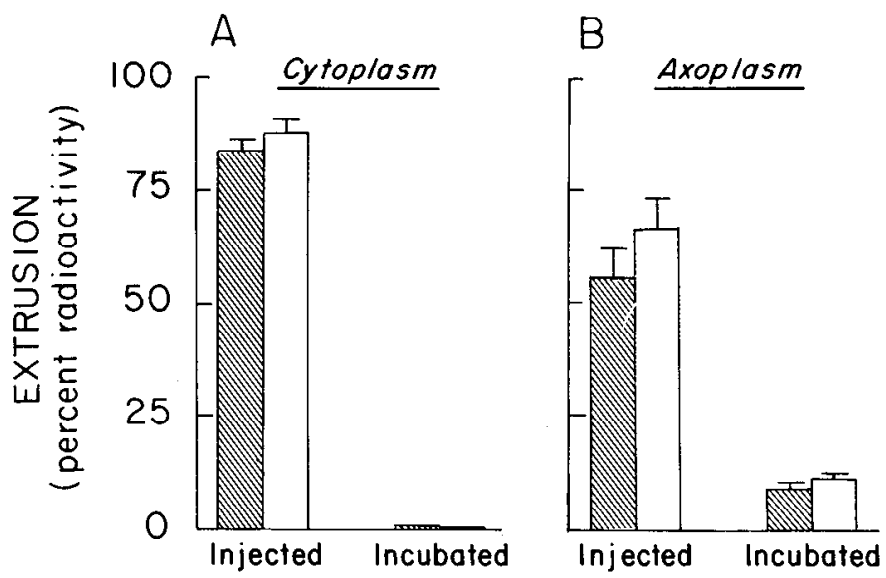

Figure 7. Extrusion of ${ }^{3} \mathrm{H}$-glycoprotein (blank bars) and ${ }^{3} \mathrm{H}$ glycolipid (hatched bars) from R2's cell body and axon. $A$, Cytoplasm, R2's cell body was removed from the ganglion after intrasomatic injection or incubation. ${ }^{3} \mathrm{H}$-Glycoconjugate extruded by hand dissection ("Materials and Methods") is presented as a percentage of the total. $B$, Axoplasm, after injection of $\left[{ }^{3} \mathrm{H}\right] \mathrm{GalNAc}$ into R2's cell body or incubation of the right connective in the presence of $\left[{ }^{3} \mathrm{H}\right]$ GalNAc, the right connective was passed through the tines of forceps (see "Materials and Methods"). Glycoconjugate extruded from the connective is presented as a percentage of the total. It is difficult to avoid rupturing some labeled supporting cells in the sheath of the connective during this procedure, and this was probably responsible for the presence of the $11 \%$ of ${ }^{3} \mathrm{H}$-glycoprotein and $9 \%$ of ${ }^{3} \mathrm{H}$-glycolipid in the extruded material. ministering the precursor has been shown by autoradiography to label glycoprotein only in the supporting cells and glia that surround axons (Ambron and Treistman, 1977). A much smaller proportion of the radioactivity in glycoprotein and glycolipid was extruded from the axon after incubation (Fig. 7B). Moreover, the chromatographic pattern of these lipids from the right connective is different from that seen after injection of the labeled sugar (Fig. 3); glycolipids A and B are absent from glial cells. Instead, two other highly polar lipids are present. Similarly, the lipids formed in the tissue of the abdominal ganglion surrounding R2's cell body are different from those synthesized within the neuron (Fig. 3).

To rule out possible variations in the tine pressure used to extrude axoplasm between those experiments in which cells were injected and those in which the tissue was incubated, we injected the cell body of $\mathrm{R} 2$ with $\left[{ }^{3} \mathrm{H}\right]$ GalNAc while incubating the nervous system in $\left[{ }^{14} \mathrm{C}\right]$ fucose. Using double label scintillation counting, we determined that $77 \%$ of ${ }^{3} \mathrm{H}$-glycolipid and $91 \%$ of ${ }^{3} \mathrm{H}$ glycoprotein were extruded from the connective, while only $16 \%$ of ${ }^{14} \mathrm{C}$-glycolipid and $8 \%$ of ${ }^{14} \mathrm{C}$-glycoprotein were extruded. These results are similar to those obtained in the single label experiments above, indicating that there was no bias in technique between the injection and the incubation experiments.

Fast axonal transport of glycolipid. We used colchicine to show that the newly synthesized ${ }^{3} \mathrm{H}$-glycolipids are rapidly transported along R2's axon. This drug blocks rapid axonal transport in Aplysia (Goldman et al., 1976; Treistman and Schwartz, 1977) but allows soluble radioactive precursors to diffuse into the axon. A colchicine $(10 \mathrm{mM})$ cuff around the proximal portion of the connective inhibited the appearance of ${ }^{3} \mathrm{H}$-glycolipid in the axon by $95 \pm 1 \%(n=3)$ and ${ }^{3} \mathrm{H}$-glycoprotein by $97 \pm 3 \%(n$ $=3$ ). Incorporation of injected precursor into glycolipid or glycoprotein in the cell body was not reduced in the presence of the cuff, and the usual chromatographic pattern of ${ }^{3} \mathrm{H}$-glycolipids was obtained from the cell body (not shown). On the other hand, chromatography of the radioactivity from the region of the axon distal to the cuff revealed the same component seen after intra-axonal injection (Fig. 6C).

Additional evidence that glycolipid moves by fast transport was provided by examining the distribution of labeled lipid along the axon at various times after intrasomatic injection of $\left.{ }^{3} \mathrm{H}\right]$ GalNAc. By $15 \mathrm{hr}$ not only was substantial ${ }^{3} \mathrm{H}$-glycolipid found in the axon 2 to $3 \mathrm{~cm}$ distal to the cell body, but it also was distributed in waves similar to those found for other rapidly transported constituents in single axons (Ambron et al., 1974b; 1981b; Goldman et al., 1976). As the interval after injection increased, increasing amounts of the glycolipid were found further out along the axon.

It is difficult to determine rates of transport from these distributions because the moving front cannot be defined precisely. Goldberg et al. (1976) devised a method of graphing transport data that permits reliable comparison of the distributions of label between axons in different specimens. According to this method, the fraction of the label distal to each 1-mm point along the axon is plotted as a function of the distance from the cell body. The 
distributions of ${ }^{3} \mathrm{H}$-glycolipids and ${ }^{3} \mathrm{H}$-glycoproteins plotted in this way overlap precisely for experiments at 5 , 10,15 , or $22 \mathrm{hr}$ after injection and are quite different from the distributions of acid-soluble radioactivity which moves by diffusion. These distributions are shown at 15 hr (Fig. 8). By comparing the displacements at $15^{\circ} \mathrm{C}$ of the distalmost $0.5 \%$ of the total neuronal radioactivity in ${ }^{3} \mathrm{H}$-glycolipid at 10,15 , and $22 \mathrm{hr}$ after injection, we estimate the rate of transport to range from 40 to 70 $\mathrm{mm} /$ day.

Coordinate export of glycoprotein and glycolipid. The similarity in the kinetics of export for glycoprotein and glycolipid indicated that they may be inserted into membranes together. Additional evidence in favor of this idea was obtained by using anisomycin. Brief exposure to this inhibitor of protein synthesis blocks export of newly synthesized membrane glycoproteins from the cell body into the axon (Ambron et al., 1975). Treatment of the isolated nervous system with anisomycin 4 to $5 \mathrm{hr}$ before intrasomatic injection of $\left[{ }^{3} \mathrm{H}\right] \mathrm{GalNAc}$ did not reduce incorporation into ${ }^{3} \mathrm{H}$-glycolipid in the cell body, but the appearance in the axon of both ${ }^{3} \mathrm{H}$-glycolipid and ${ }^{3} \mathrm{H}$ glycoprotein was reduced by more than $90 \%$ (Fig. 9). As with colchicine, the appearance of soluble precursors in

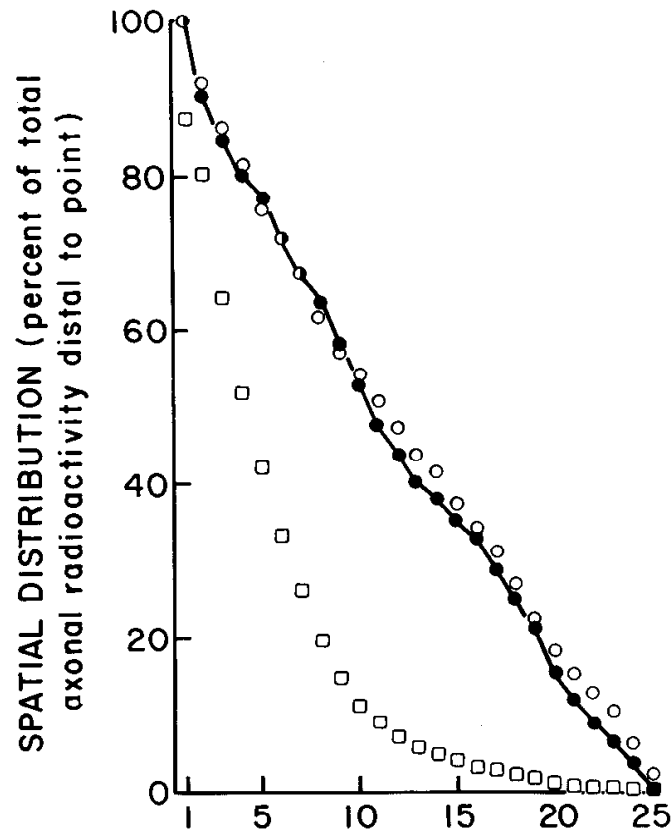

DISTANCE ALONG AXON $(\mathrm{cm})$

Figure 8. Spatial distribution of ${ }^{3} \mathrm{H}$-glycoconjugates and acidsoluble radioactivity along the axon of $\mathrm{R} 215 \mathrm{hr}$ after intrasomatic injection of $\left[{ }^{3} \mathrm{H}\right]$ GalNAc. The amounts of a component $\left({ }^{3} \mathrm{H}\right.$-glycolipid, ${ }^{3} \mathrm{H}$-glycoprotein, or soluble) distal to each point along the axon are determined; these values, expressed as a percentage of the total radioactive component in the axon, are then plotted as a function of distance from the cell body. ${ }^{3} \mathrm{H}$-Glycolipid (total radioactivity, $11,100 \mathrm{cpm}$ ). $\mathrm{O}$, Particulate ${ }^{3} \mathrm{H}$-glycoprotein $(927,000 \mathrm{cpm}) . \square$, Acid-soluble radioactivity $(220,300 \mathrm{cpm})$. After injection, tissue was frozen and the right connective was severed just adjacent to the cell body in the abdominal ganglion. The connective was cut into $1-\mathrm{mm}$ sequential segments, and each segment was homogenized and fractionated as described under "Materials and Methods."
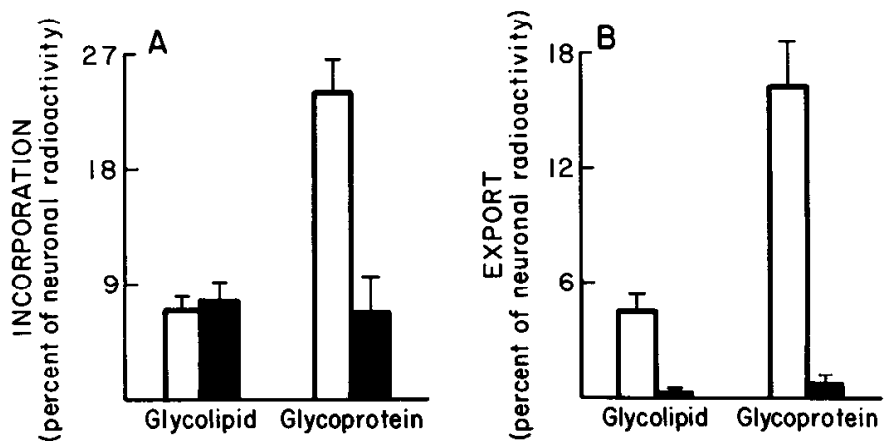

Figure 9. Effects of anisomycin on the incorporation of $\left[{ }^{3} \mathrm{H}\right]$ GalNAc into glycoconjugates and on their export from the cell body. Prior to intrasomatic injection, nervous systems were exposed to anisomycin (solid bars) or maintained in the supplemented sea water (open bars). The cell body and axon were separated and fractionated $22 \mathrm{hr}$ after the injection (see "Materials and Methods"). A, Incorporation, ${ }^{3} \mathrm{H}$-glycoconjugates in the cell body are shown as a percentage of the total radioactivity in the neuron. $B$, Export, ${ }^{3} \mathrm{H}$-glycoconjugates in the axon are shown as a percentage of the total radioactivity in the neuron.

the axon is not inhibited by the drug, presumably because they diffuse into the axon. Chromatography of a chloroform:methanol extract from the particulate fraction of R2's axon after treatment with anisomycin yielded only one labeled component. This material migrated together with the axonal component seen after intra-axonal injection (Fig. 6D) and was swept to the front of the chromatogram with aqueous sodium tetraborate (not shown).

\section{Discussion}

Biochemical characterization of the ${ }^{3} \mathrm{H}$-glycolipids. The chemical composition of the glycolipids synthesized by $\mathrm{R} 2$ after intrasomatic injection of $\left[{ }^{3} \mathrm{H}\right]$ GalNAc indicates that they are a class of sphingophosphonoglycolipids. Glycolipids A and B, like certain gangliosides of vertebrate cell membranes, are negatively charged and highly polar. In vertebrates, gangliosides contribute to the anionic surface charge of the membrane. They also serve as receptors, and it has been suggested that gangliosides impart specificity to neuronal membranes (Yamakawa and Nagai, 1978). Gangliosides are not present in most invertebrates, however, and are absent from the Aplysia nervous system (Komai et al., 1973; Nören and Svennerholm, 1973; Ng and Dain, 1976). Since it is likely that the functions mediated by gangliosides are assumed by other lipids in invertebrates, we suggest that the sphingophosphonoglycolipids fulfill the function of gangliosides in Aplysia.

The sphingophosphonoglycolipids found in R2 seem to be constituents of a heterogeneous family of related glycolipids. SGL-II, which was isolated from the skin of Aplysia kurodai (Araki et al., 1980), has properties similar to glycolipid A but differs with regard to sugar composition. Similarly, as shown in Figure 3, the glycolipid composition of glial cells and supporting tissue that surround R2 includes several highly polar species that are different from glycolipids A and B of R2. We also found differences in the glycolipids of $\mathrm{R} 2$ and of the giant cerebral neuron (GCN), an identified serotonergic neuron. GCN lacks glycolipid A, one of the major compo- 
nents of R2's membranes (Sherbany, 1981). Differences between GCN and R2 have also been found in membrane glycoproteins (Ambron et al., 1980). Taken together, these observations suggest that characteristic glycoconjugates serve to distinguish the membranes of different cells, and this may be related to specificity of function.

Origin of glycolipids in the cell body. It is the general view that essentially all macromolecular constituents of neuronal membranes are synthesized in the nerve cell body (Schwartz, 1979; Grafstein and Forman, 1980). We explored several possible origins of R2's glycolipids because extrasomatic synthesis of some macromolecules has been previously described. For example, the transfer of proteins from glial cells to axoplasm has been demonstrated in the squid (Lasek et al., 1977). Moreover, the origin of the various types of lipids that constitute neuronal membranes may differ. Droz et al. (1978) have suggested that rapidly transported phospholipids are transferred from the axon to myelin, while in peripheral nerves, phosphatidylcholine synthesized by Schwann cells finds its way into axons (Kumara-Siri and Gould, 1980).

Several lines of evidence support the idea that the rapidly transported glycolipids found in R2's axon originates in the cell body. First, the axonal ${ }^{3} \mathrm{H}$-glycolipids are chemically indistinguishable from those labeled in the cell body. Second, the axon is unable to incorporate $\left[{ }^{3} \mathrm{H}\right] \mathrm{GalNAc}$ into glycolipid. This is true whether the precursor is injected directly into the axon or is allowed to diffuse into the axon from the cell body (Fig. 6). Restriction of the synthesis of glycolipids to the cell body is to be expected because Golgi membranes are the sole site of fucosylation (Morré, 1977). Finally, it is unlikely that the axonal glycolipids originate in glial cells because the polar glycolipids made in glia differ chemically from those synthesized in the neuron.

Coordinated synthesis of ${ }^{3} \mathrm{H}$-glycolipids and ${ }^{3} \mathrm{H}$-glycoproteins. Synthesis and distribution of glycolipids and glycoproteins in R2 seem to be coordinated. The extent of incorporation of injected sugar into both glycoprotein and glycolipid showed a similar increase with time after intrasomatic injection and a similar dependence on the amount of $\left[{ }^{3} \mathrm{H}\right]$ GalNAc injected (Ambron et al., 1981a; Sherbany, 1981). In addition, export into the axon of both kinds of glycoconjugates followed the same kinetics, and both were transported rapidly along the axon at similar rates. Glycolipids and glycoproteins are both constituents of membranes; presumably they are coordinately distributed because both are inserted into membranes of the same population of organelles.

Ambron et al. (1975) found that the export of ${ }^{3} \mathrm{H}$ glycoproteins from R2's cell body into its axon is much more profoundly blocked than is their glycosylation by the application of anisomycin, a specific inhibitor of protein synthesis in Aplysia (Schwartz et al., 1971). This observation led to the suggestion that continued synthesis of polypeptide is necessary for the export of newly synthesized membrane constituents (Ambron et al., 1975). Similar observations have been made in the nervous systems of other animals, where inhibiting the synthesis of one type of membrane constituent results in blocking the export of all newly synthesized organelles (reviewed by Schwartz, 1979; Longo and Hammerschlag, 1980). In the serotonergic GCN, Goldberg et al. (1978) showed that transmitter storage granules, assembled before exposure of the neuron to the inhibitor, continue to be exported long after application of anisomycin. In our present experiments with anisomycin, we find that inhibition of protein synthesis in R2 completely blocked the export of ${ }^{3} \mathrm{H}$-glycolipids, even though their synthesis in the cell body was totally unaffected. Thus, despite the existence of a normal complement of ${ }^{3} \mathrm{H}$-glycolipid, the somatic membranes formed in the presence of anisomycin are incomplete, presumably because the glycolipids in them have been inserted without concomitant insertion of protein. This and the other instances where the export of nascent organelles is blocked by inhibitors of either protein or lipid synthesis suggest that a mechanism exists in the cell body that tickets completed organelles for export into the axon while preventing the export of organelles that are not yet complete.

\section{References}

Ambron, R. T. (1982) Differences in the distribution of specific glycoproteins among the regions of a single identified neuron. Brain Res. 239: 489-505.

Ambron, R. T., and R. A. Pieringer (1971) The metabolism of glyceride glycolipids. V. Identification of the membrane lipid formed from diglucosyl diglyceride in Streptococcus faecalis ATCC 9790 as an acylated derivative of glyceryl phosphoryl diglucosyl glycerol. J. Biol. Chem. 246: 4216-4225.

Ambron, R. T., and S. N. Treistman (1977) Glycoproteins are modified in the axon of R2, the giant neuron of Aplysia californica, after intra-axonal injection of ${ }^{3} \mathrm{H}-\mathrm{N}$-acetylgalactosamine. Brain Res. 121: 287-309.

Ambron, R. T., J. E. Goldman, E. B. Thompson, and J. H. Schwartz (1974a) Synthesis of glycoproteins in a single identified neuron of Aplysia californica. J. Cell Biol. 61: 649-664.

Ambron, R. T., J. E. Goldman, and J. H. Schwartz (1974b) Axonal transport of newly synthesized glycoproteins in a single identified neuron of Aplysia californica. J. Cell Biol. 61: $665-675$.

Ambron, R T., J. E. Goldman, and J. H. Schwartz (1975) Effect of inhibiting protein synthesis on axonal transport of membrane glycoproteins in an identified neuron of Aplysia. Brain Res. 94: 307-323.

Ambron, R. T., J. E. Goldman, L. J. Shkolnik, and J. H. Schwartz (1980) Synthesis and axonal transport of membrane glycoproteins in an identified serotonergic neuron of Aplysia. J. Neurophysiol. 43: 929-943.

Ambron, R. T., A. A. Sherbany, L. J. Shkolnik, and J. H. Schwartz (1981a) Distribution of membrane glycoproteins among organelles of a single identified neuron of Aplysia. I. Association of a ${ }^{3} \mathrm{H}$-glycoprotein with vesicles. Brain Res. 207: $17-32$.

Ambron, R. T., A. A. Sherbany, and J. H. Schwartz (1981b) Distribution of membrane glycoproteins among organelles of a single identified neuron of Aplysia. II. Isolation and characterization of glycoprotein associated with vesicles. Brain Res. 207: 33-48.

Araki, S., and M. Satake (1981) Acidic sphingoglycolipids in invertebrate nervous tissue: Presence of several kinds of sphingophosphonoglycolipids in the nervous system of Aplysia kurodai, a sea gastropod. Neurosci. Iett. 22: 179-182.

Araki, S., Y. Komai, and M. Satake (1980) A novel sphingo- 
phosphonoglycolipid containing 3-O-methylgalactose isolated from the skin of the marine gastropod Aplysia kurodai. Biochem. J. 87: 503-510.

Chien, J. L., T. Williams, and S. Basu (1973) Biosynthesis of a globoside-type glycosphingolipid by a beta- $N$-acetylgalactosaminyltransferase from embryonic chicken brain. J. Biol. Chem. 248: 1778-1785.

Droz, B., L. DiGiamberardino, H. L. Koenig, J. Boyenval, and R. Hassig (1978) Axon-myelin transfer of phospholipid components in the course of their axonal transport as visualized by radioautography. Brain Res. 155: 347-353.

Eisenstadt, M., J. E. Goldman, E. R. Kandel, H. Koike, J. Koester, and J. H. Schwartz (1973) Intrasomatic injection of radioactive precursors for studying transmitter synthesis in identified neurons of Aplysia californica. Proc. Natl. Acad. Sci. U. S. A. 70: 3371-3375.

Fishman, P. H., and R. O. Brady (1976) Biosynthesis and function of gangliosides. Science 194: 905-915.

Forman, D. S., and R. W. Ledeen (1972) Axonal transport of gangliosides in the goldfish optic nerve. Science 177:630633.

Goldberg, D. J., J. E. Goldman, and J. H. Schwartz (1976) Alterations in amounts and rates of serotonin transported in an axon of the giant cerebral neuron of Aplysia californica. J. Physiol. (Lond.) 259: 473-490.

Goldberg, D. J., J. H. Schwartz, and A. A. Sherbany (1978) Kinetic properties of normal and perturbed axonal transport of serotonin in a single identified axon. J. Physiol. (Lond.) 281: 559-579.

Goldman, J. E., K. S. Kim, and J. H. Schwartz (1976) Axonal transport of ${ }^{3} \mathrm{H}$-serotonin in an identified neuron of Aplysia californica. J. Cell Biol. 70: 304-318.

Grafstein, B., and D. Forman (1980) Intracellular transport in neurons. Physiol. Rev. 60: 1167-1283.

Holm, M. (1972) Gangliosides of the optic pathway: Biosynthesis and biodegradation studied in vivo. J. Neurochem. 19: 623-629.

Komai, Y., S. Matsukawa, and M. Satake (1973) Lipid composition of the nervous tissue of the invertebrates Aplysia kurodai (gastropod) and Cambarus clarki (arthropod). Biochim. Biophys. Acta 316: 271-281.

Kumara-Siri, M. H., and R. M. Gould (1980) Enzymes of phospholipid synthesis: Axonal versus Schwann cell distribution. Brain Res. 186: 315-330.

Lasek, R. J., H. Gainer, and J. Barker (1977) Cell-to-cell transfer of glial proteins to the squid giant axon. J. Cell Biol. 74: 501-523.

Ledeen, R. W., J. A. Skrivanek, L. J. Tirri, R. K. Margolis, and R. U. Margolis (1976) Gangliosides of the neuron: Localization and origin. Adv. Exp. Med. Biol. 17: 83-103.

Longo, F. M., and R. Hammerschlag (1980) Relation of somal lipid synthesis to the fast axonal transport of protein and lipid. Brain Res. 193: 471-485.

Morré, D. J. (1977) The Golgi apparatus and membrane biogenesis. In The Synthesis, Assembly and Turnover of Cell Surface Components, G. Poste and G. L. Nicholson, eds., pp. 1-83, Elsevier North Holland Biomedical Press, Amsterdam.

Naughton, M. A., and H. Hagopian (1962) Some applications of two-dimensional ionophoresis. Anal. Biochem. 3: 276-284.

Ng, S.-S., and J. A. Dain (1976) The natural occurrence of sialic acids. In Biological Roles of Sialic Acid, A. Rosenberg and C. L. Schengrund, eds., pp. 59-102, Plenum Press, New York.

Nören, R., and L. Svennerholm (1973) Lipid composition and phosphoglyceride fatty acid patterns of the nervous tissue in squid, lobster, dogfish and cod. Zh. Evol. Biochim. Fiziol. 9: $225-234$.

Rayport, S. G., R. T. Ambron, and J. Babiarz (1983) Identified cholinergic neurons R2 and LP1 control mucus release in Aplysia. J. Neurophysiol. 49: 864-876.

Rouser, G., G. Kritchevsky, and A. Yamamoto (1967) Column chromatographic and associated procedures for separation and determination of phosphatides and glycolipids. In Lipid Chromatographic Analysis, G. V. Marinetti, ed., Vol. 1, pp. 99-161, Marcel Dekker, New York.

Schwartz, J. H. (1979) Axonal transport: Components, mechanisms, and specificity. Annu. Rev. Neurosci. 2: 467-504.

Schwartz, J. H., V. F. Castellucci, and E. R. Kandel (1971) Functioning of identified neurons and synapses in the abdominal ganglion of Aplysia in the absence of protein synthesis. J. Neurophysiol. 34: 939-953.

Sherbany, A. A. (1981) Regional biosynthesis and axonal transport of membrane glycolipids in the nervous system of the marine mollusc, Aplysia californica. Ph.D. thesis, New York University. In Dissertation Abstracts International, Vol. 43, No. 2, University Microfilms, Ann Arbor, MI.

Sherbany, A. A., R. T. Ambron, and J. H. Schwartz (1979) Membrane glycolipids: Regional synthesis and axonal transport in a single identified neuron of Aplysia californica. Science 203: 78-81.

Thompson, E. B., J. H. Schwartz, and E. R. Kandel (1976) A radioautographic analysis in the light and electron microscope of identified Aplysia neurons and the processes after intrasomatic injection of $\mathrm{L}^{-}{ }^{3} \mathrm{H}$-fucose. Brain Res. 112: 251281.

Treistman, S. N., and J. H. Schwartz (1977) Metabolism of acetylcholine in the nervous system of Aplysia californica. IV. Studies of an identified cholinergic axon. J. Gen. Physiol. 69: $725-741$.

Yamakawa, T., and Y. Nagai (1978) Glycolipids at the cell surface and their biological functions. Trends. Biochem. Sci. 3: $128-131$. 